\title{
Cultura Cultura
}

\section{HALLWARD, Peter, Absolutely Postcolonial: Writing between the Singular and the Specific}

\section{Marcos Cardão}

\section{(2) OpenEdition}

\section{Journals}

\section{Edição electrónica}

URL: http://journals.openedition.org/cultura/916

DOI: 10.4000/cultura.916

ISSN: 2183-2021

\section{Editora}

Centro de História da Cultura

\section{Edição impressa}

Data de publição: 1 junho 2007

Paginação: 286-290

ISSN: 0870-4546

\section{Refêrencia eletrónica}

Marcos Cardão, " HALLWARD, Peter, Absolutely Postcolonial: Writing between the Singular and the Specific », Cultura [Online], Vol. 24 | 2007, posto online no dia 10 outubro 2013, consultado a 22 setembro 2020. URL : http://journals.openedition.org/cultura/916 ; DOI : https://doi.org/10.4000/ cultura.916 


\title{
HALLWARD, Peter, Absolutely Postcolonial: Writing between the Singular and the Specific, Manchester, Manchester University Press, 2001, 433 pp.
}

\author{
Marcos Cardão
}

Na contracapa deste livro o filósofo esloveno Slavoj Žižek escreve:"finalmente a voz que secretamente todos estávamos à espera (...) se cada livro pudesse ser uma arma, este sê-lo-ia!" Da exclamação passemos à interrogação: será que nos dias que correm ainda existem livros que recusem o cepticismo reinante e abalem os consensos estabelecidos?

Findo o século das rupturas e das catástrofes, encontramo-nos entre paradigmas, um local de eterno presente, dominado por falsos consensos, singularidades e pragmatismo. Visando elaborar uma filosofia pós-colonial da subjectividade, este livro, árido mas eficiente em termos pedagógicos, desafia criticamente as categorias estabelecidas para interpretação do mundo, em particular as nomenclaturas avançadas pelas teorias pós-coloniais. Estas inicialmente enfatizaram a fragmentação, o que supostamente conduziria a uma nova atenção ao contexto e à pluralidade das posições do sujeito; porém, estas suposições rapidamente resvalaram para uma metacategoria "indiferenciada" em que tudo se tornou indistinto, singular e particular.

É no impasse teórico dos estudos pós-coloniais que Peter Hallward - através de um aturado estudo literário das obras do caribenho Edouard Glissant, do norte-americano Charles Johnson, do argelino Mohammed Dib e do cubano Severo Sarduy - procura reafirmar a validade da literatura, independentemente das leituras parciais da política ou do interpretativismo desconstrucionista. Este projecto reenvia-nos para a filiação original dos estudos pós-coloniais que, no que diz respeito à literatura, foram recorrentemente breves, insubstanciais e, por vezes, simplesmente anedóticos. ${ }^{1}$

Peter Hallward, professor de Filosofia Moderna na Universidade de Middlessex, publicou Absolutely Postcolonial em 2001 e, posteriormente, tornou-se um divulgador da obra filosófica de Alain Badiou no mundo anglófono, com a publicação de Badiou: A Subject to Truth (2003); Think Again: Alain Badiou and the Future of Philosophy (2004), um volume editado por Peter Hallward e Slavoj Žižek; e o recente Out of this World: Deleuze and the Philosophy of Creation (2006). São ecos destes autores, entre outros, que perpassam neste trabalho controverso.

\footnotetext{
"Having long since absorbed the boundary-blurring lessons of deconstruction, many postcolonial literary critics seem embarrassed by what remains of their disciplinary affiliation. Most postcolonial readings are brief, often insubstantial, sometimes simply anecdotal" (p. 335).
} 
Absolutely Postcolonial está dividido em cinco capítulos, quatro deles dedicados aos romancistas referidos, seguidos por excursus no final de cada capítulo, nos quais o autor expõe os seus conceitos, ao mesmo tempo que critica os conceitos hegemónicos da ordem pós-moderna: híbrido, intersticial, contingente, singular, indeterminado e unívoco.

$\mathrm{Na}$ introdução são analisados dois conceitos fulcrais na tese do autor: singular e específico, que designam dois pólos abstractos distintos. O primeiro consiste num processo interno de individuação não-relacional e particular que substitui a historicidade pela contingência; e o segundo, por essência relacional, pressupõe deliberações, escolhas, riscos e potencia novos universalismos ${ }^{2}$. Hallward argumenta que o discurso pós-colonial está acoplado a uma empresa essencialmente singular, autoconstituída e auto-regulada, que resiste à mediação, logo não tem objecto específico susceptível de interpretação. Não se trata apenas de uma crítica terminológica à singularização dos conceitos (agência, contexto, eu, outro, política, cultura) postos em prática pela teoria pós-colonial, é também uma clara condenação da abordagem singular de raiz deleuziana ${ }^{3}$ operada por outras teorias, em particular pela teoria literária.

Para resistir à tendência da singularização o autor propõe uma reconceptualização teórica global e uma inovação política incisiva ${ }^{4}$. Em primeiro lugar, preencher a lacuna que existe actualmente nos estudos pós-coloniais que, segundo Hallward, fazem uma leitura dos textos literários de forma "apologética", "particularista” e "parcial”, em vez de efectivarem uma leitura detalha dos textos "nos seus próprios termos". Em segundo lugar, reconceptualizar o específico, não como sinónimo do particular, intrínseco ou local, mas como uma equação activa e subjectiva da relacionalidade enquanto tal. Em terceiro lugar, quebrar o laço entre política e cultura, não cedendo à omnipresença da cultura reificada na sociedade contemporânea nem ao comunitarismo identitário reinante. Em quarto lugar, reafirmar a autonomia limitada do campo literário e da sua capacidade de criação e invenção de palavras não submetidas às qualidades específicas que governam a sua produção;

2 "Roughly speaking, a singular mode of individuation proceeds internally, through a process that creates its own medium of existence or expansion, whereas specific mode operates, through the active negotiation of relations and the deliberate taking sides, choices and risks, in a domain and under constraints that are external to these takings" (p.XII).

3 "Deleuze accepts that there has only ever been one ontological proposition: Being is univocal. (...) Deleuzian univocity is the condition of radically singular difference, i.e. difference free from the limits of constituent relations between the differed. Difference rests entirely in the 'Creating', so to speak" (p. 12). Ver também Peter Hallward, Out of this World:Deleuze and the Philosophy of Creation, London, Verso Books, 2006.

4 "Postcolonial writing is indeed worthy of systematic and thorough interpretation, but such interpretation can only proceed on the basis of an unapologetically contemporary theoretical framework" (p. XIX). 
impedindo deste modo a exclusão da literatura para uma espécie de "regresso dos deuses" romântico, ou para afirmação de um didactismo do "como deve ser" do realismo socialista. Por fim, retomar a palavra/significado universal, com vista a prescrever as condições de possibilidade válidas para qualquer relação independentemente das suas especificidades e contingências.

Recuperemos a questão do singular e do específico na abordagem que o autor faz do trabalho de Glissant, Johnson, Dib e Sarduy que, apesar da sua origem radicalmente diversa, apresentam uma concepção singular da realidade. Pese embora a irredutibilidade das posições e trajectórias de cada dos autores: Dib partilha uma versão do misticismo islâmico; Sarduy e Johnson partilham uma versão do budismo; e Glissant segue o modelo "tout-monde", ou seja, uma versão nomadológica de origem deleuziana. ${ }^{5} \mathrm{O}$ singular, como nomádico e não relacional, afirma a passividade e a univocidade de cada indivíduo; em contraponto, a categoria de específico valoriza a relação do sujeito em cada situação/contexto e sugere a preeminência do sujeito sobre o objecto. $O$ projecto seria produzir um conceito de sujeito que não tivesse como sustentáculo o objecto.

Hallward socorre-se de Franz Fanon para explicar este processo: um indivíduo torna-se sujeito na sequência de um processo militante de descolonização. Este processo relacional conduz à universalidade (um universal político), "desobstruindo"6 o sujeito que anteriormente estava constrangido pela situação colonial. Todavia, a eliminação do constrangimento colonial (ou outro) não produz necessariamente o específico, pois este processo só é possível através de sucessivas "desobstruções". Pretende-se no fundo a conversão das relações objectivadas e singulares em relações subjectivas e específicas. Em resumo, parece-nos claro que a ênfase na relacionalidade ${ }^{7}$ e nas taxinomias de específico e singular reconduzem-nos às noções de sujeito e objecto, ou não será o sujeito específico ("desobstruído") um sinónimo contemporâneo do sujeito universal emancipado? Se assim é, quais são os trilhos dessa emancipação?

5 "I will argue that Glissant's later concept of the Tout-monde, or whole-world, is not fundamentally relational in the specific sense used in the present study, so much as the medium and expression of a singular whirlwind of self-differentiation and constant or 'chaotic' metamorphosis. Like Deleuze, Glissant arrives at a theory of la Relation defined primarily by its transcendence of relations with or between specific individuals" (p. 67).

- Que corresponde a "Despecification" no original em inglês: "the subject qua subject only comes into being through and as a result of the militant process of decolonisation as such. Despecification - here the explosion of colonial constraints - is itself the process of subjectivation" (p. 50).

7 "Relationality, in short, is not itself dialectical (even though many relations are inflected in a dialectic way). Relation is the unchanging medium and transcendental condition of our existence. (...) Relation does not distribute its 'terms' in a singular dissemination, but provides the medium in which these terms persist and change" (p. 252). 
Aqui entramos no ponto mais espinhoso da análise de Hallward, que propõe o regresso específico do estado-nação para fazer face aos "minimercados" particularistas do culturalismo contemporâneo; desvalorizando assim a resistência liminar ao estado-nação por parte das teorias pós-coloniais que o consideram um obstáculo à dinâmica singular de crioulização cultural. Hallward defende um nacionalismo neo-jacobino inclusivo e solidário, indiferente às especificidades particulares, que assegure à acção política alguma durabilidade. Esta reabilitação, excessivamente voluntarista, pressupõe que o estado-nação se encarregue da "transubstanciação" de comunidades locais e das suas tradições na nação moderna ("comunidade imaginada") que, independentemente das desigualdades, engendra laços de camaradagem horizontais entre os seus constituintes. Nesta lógica, o estado-nação "sublimaria" as formas locais de identificação, impondo-lhes uma significação "patriótica" universal e, contiguamente, posicionar-se-ia como uma espécie de fronteira pseudonatural da economia de mercado, separando o comércio "interno" do comércio "externo". Esta forma de nacionalismo económico, ou seja, a "sublimação" da actividade económica elevada à categoria de coisa étnica, legitimada enquanto contribuição patriótica para a grandeza das nações, esbarra evidentemente na lógica imanente ao Capital, cuja natureza "transnacional" é, por definição, indiferente às fronteiras do estado-nação.

Curiosamente a perspectiva de reabilitação do estado-nação proposta neste livro coincide com o argumento universalista que, para além de transcender as contingências empíricas, prescreve critérios válidos para todas as relações numa dada situação. Neste caso a legitimidade não decorre da integridade de uma dada relação particular (do estilo empregador/empregado ou senhor/escravo) mas sim do critério normativo aplicado a cada relação em geral, o que implica deliberação, decisão e tomada de partido (militante e subjectiva), ou seja, a universalidade é um resultado excepcional que tem a sua origem num momento, a consequência de uma decisão e uma "maneira de ser" que transcende um saber ou uma representação. A concepção específica da relacionalidade radica num "surgimento incalculável" que requer uma disposição subjectiva transversal a todas as representações e indiscernível ao tempo, ou seja, deve ser necessariamente a-histórico e sem predicados descritivos preexistentes. Nesta passagem Hallward repercute nitidamente o trabalho événementiel de Alain Badiou. ${ }^{8}$

8 Ver Alain Badiou, L'Être et l'événement, Paris, Éditions du Seuil, 1988; no qual enuncia e valida (filosoficamente) a equação matemática = ontologia; e articula os pontos nodais da sua filosofia: Ser, Acontecimento e Sujeito. Para Badiou há quatro "procedimentos genéricos": o amor , a arte (criação), a ciência (conceptual) e a política (emancipadora). A Verdade irrompe de um destes quatro Acontecimentos e tem como finalidade um Sujeito que é fiel às consequências do Acontecimento. Este impulso de fidelidade é uma "escolha pura" indiscernível, pois a Verdade é ilimitada nas suas formas; inominável, porque não tem nomes nem é legislável; indecidível, no sentido em que a Verdade não é uma garantia permanente, ela acontece 
Em suma, Absolutely Postcolonial é um manifesto teórico para o século XXI que versa uma multiplicidade de temas que vão desde a distinção entre política e cultura; a reafirmação de uma certa autonomia do campo literário; a adopção de uma política específica para fazer face às tendências globais eminentemente singulares; até à demonstração que, contra todas as evidências em contrário, a era das invenções políticas está longe de ter terminado.

Os argumentos, a densidade e a perspicácia do livro de Peter Hallward são inegáveis, mas será que este "exercício de pensamento" é transponível para outros campos do saber? Que consequências trariam a operacionalidade de tais teorias? No caso das Ciências Sociais acreditamos que a tónica da relacionalidade "desobstruiria" os saberes compartimentados de cada disciplina, por vezes excessivamente singulares e presos a "jogos de linguagem" particulares, e abalaria o modo de funcionamento do trabalho académico corrente (explicativo, verificável, empírico, solucionador de problemas, etc). A dimensão do "aparato teórico" seria crucial para a efectivação de um projecto transdisciplinar que possibilitasse elaborar "metacomentários"9 capazes de traduzir criticamente a realidade, minando desta forma as fronteiras disciplinares do trabalho académico. Nesta linha, a abordagem de Peter Hallward, ainda que incompleta e contraditória, é uma lufada de ar fresco que visa interpretar, da forma mais alargada possível, os vários contextos específicos, problematizando, ao mesmo tempo, os procedimentos dessa análise.

e é perpetuamente verificável; e genérica, pois a Verdade não pertence ao conhecimento nem é representável. Estes conceitos, entre outros, são desenvolvidos no segundo tomo de Alain Badiou, Logique des mondes. L'Être et l'événement 2, Paris, Éditions du Seuil, 2006; onde prossegue 'formalizações lógicas' que (re)inventem a metafísica contemporânea.

9 Ver entrevista a Frederic Jameson conduzida por Xudong Zhang, "Marxism and the Historicity Theory", publicada no New Literary History, 29 (3) (1998), pp. 353-383; in The Jameson Reader, Ed. Michael Hardt e Kathi Weeks, Blackwell, Oxford, 2004 (2000) pp. 149-163. 